\title{
Pengaruh Komunikasi Antarpribadi Bermedia Internet terhadap Persahabatan Mahasiswa di Dunia Maya
}

\begin{abstract}
Anne Ratnasari
ABSTRACT

The problem which was studied is the influence of the Internet mediated interpersonal communication on online student friendship. Some communication modes are available on the Internet however this research focused on the use of chat facility to establish student online friendship. The quantitative aproach was applied by conducting explanatory survey method to determine the influence of the Internet mediated interpersonal communication through Chatting on student online friendship. Some aspects which were studied on this research are Chatting intensity, Chatting appeal, Chatting dependency, and communication messages while Chatting. All those aspects were considered their influence on student online friendship.

Population of this research is students who used chat facility in the Kubus Net Bandung. The data of this research was analyzed using path analysis to determine the level of influence of each research variable. The result of influence test on the four hypothesis either partially or simultaneously showed that there was an influence of Chatting intencity, Chatting appeal, Chatting dependency, and communication messages while Chatting on the student online friendship of the student who use chat facility. The four aspects of Chatting influence differently on student online friendship. Chatting message had more influence than Chatting intensity, dependency and Chatting appeal to the student online friendship.
\end{abstract}

Kata kunci: CMC, internet, komunikasi antarpribadi

\section{Pendahuluan}

\subsection{Latar Belakang Masalah}

Sebagai makhluk sosial, manusia memerlukan komunikasi untuk berhubungan secara berarti satu dengan yang lain. Berbagai keterbatasan yang dahulu dialami dalam berhubungan dengan orang lain terutama hambatan jarak, lambat laun dapat diatasi dengan kehadiran teknologi komunikasi, khususnya Internet.

Komunikasi antarpribadi bermedia Internet membawa pengaruh yang besar terhadap cara berkomunikasi yang biasa dilakukan manusia. Komunikasi ini memiliki fungsi menginformasikan, menjelaskan, menghibur, transmisi budaya, dan sebagai medium interaksi sosial (Baldwin et al., 2004:248).

Internet sebagai media komunikasi menjadi sangat populer di masyarakat karena fasilitas yang dimilikinya. Salah satunya adalah fasilitas chat, yaitu fasilitas yang memungkinkan terjadinya komunikasi interaktif seseorang dengan orang lain, sedangkan aktivitas komunikasi yang dilakukan penggunanya disebut chatting, yaitu "suatu 
bentuk percakapan tertulis mengenai topik pembicaraan tertentu dalam satu waktu yang sebenarnya" (Sidharta, 1996:153).

Melakukan pertemanan atau persahabatan merupakan salah satu kebutuhan manusia untuk memiliki hubungan yang berarti dengan orang lain. Chatting memungkinkan seseorang membuka perkenalan sebagai sebuah bentuk hubungan baru dengan teman online, karena "ketika chatting banyak orang berteman akrab tanpa pernah berjumpa secara langsung" (LaQuey, 1997:48). Komunikasi jagat maya tersebut disebut sebagai "medium untuk mengumpulkan orang, kawan, kerabat, yang telah terpisahkan oleh tempat tinggal".

Pengguna fasilitas chat di internet berkomunikasi antarpribadi baik secara lokal, maupun global dengan mereka yang tidak saling mengenal (anonim), kemudian menjalin hubungan di antara mereka. Beberapa penelitian yang mendukung hal ini seperti penelitian Rintel, et al.(2001), Maria (2003), Chan \& Cheng (2004). Dengan demikian komunikasi tersebut menggambarkan aktivitas yang bersifat fungsional. Namun di sisi lain, anonimitas tersebut memungkinkan para chatter untuk berkomunikasi antarpribadi yang secara sengaja menutupi atau mengganti data diri yang sesungguhnya dalam berhubungan di komunitas virtual (Bromberg dalam Shields, 1988, Rheingold, 1998, dan Van Dijk,1999). Internet juga dapat menyebabkan penggunanya mengalami kecanduan. Rasa senang yang diperoleh dari berinternet menyebabkan seseorang lupa waktu, sehingga menimbulkan ketergantungan yang mendatangkan masalah (Young, 1998, dan Athari, 2004). Hal ini memperlihatkan efek disfungsional komunikasi antarpribadi bermedia Internet.

Berdasarkan uraian tersebut melakukan chatting dapat mendatangkan manfaat (fungsional) dan masalah (disfungsional). Hasil-hasil penelitian mengenai hal itu memperlihatkan bahwa kehadiran teknologi komunikasi baru, khususnya internet yang saat ini telah demikian menyebar di lingkungan masyarakat tidak terlepas dari manfaat yang positif dan dampak buruknya. Kajian yang dilakukan dalam penelitian ini berusaha untuk mengungkapkan sisi baik dan sisi buruk dalam penggunaan chatting di internet sebagai modus baru memperoleh pertemanan atau persahabatan di dunia maya.

Dalam penelitian ini diteliti bagaimana aktivitas mahasiswa melakukan komunikasi antarpribadi menggunakan fasilitas chat di internet yang dilihat pada segi intensitas, daya tarik, ketergantungan melakukan chatting, dan pesan komunikasi pada saat chatting pengaruhnya terhadap persahabatan di dunia maya sebagai salah satu bentuk interaksi sosial yang baru.

Salah satu cara dalam memelihara hubungan di dunia maya adalah dengan berteman. Karena mahasiswa sebagai remaja yang berada di masa pencarian jati diri memerlukan kehadiran teman atau sahabat yang memungkinkan mereka mengungkapkan perasaan, berbagi informasi, dan sebagainya.

Tempat penelitian ini dipusatkan pada pengguna yang mengakses internet di Kubus Net Bandung. Perusahaan ini merupakan salah satu tempat penyewaan Internet terbesar di Bandung. Lokasinya berdekatan dengan kampus, dan pengunjungnya mayoritas remaja yang berstatus mahasiswa.

Untuk mengetahui permasalahan tersebut, perlu digali lebih mendalam mengenai komunikasi bermedia internet di kalangan mahasiswa. Dengan demikian maka dipandang penting untuk melakukan penelitian mengenai pengaruh komunikasi antarpribadi bermedia internet menggunakan fasilitas chat terhadap persahabatan mahasiswa di dunia maya.

\subsection{Identifikasi Masalah}

(1) Sejauhmanakah pengaruh intensitas chatting di Internet terhadap persahabatan mahasiswa di dunia maya?

(2) Sejauhmanakah pengaruh daya tarik chatting di Internet terhadap persahabatan mahasiswa di dunia maya?

(3) Sejauhmanakah pengaruh ketergantungan melakukan chatting di internet berpengaruh terhadap persahabatan mahasiswa di dunia 
maya?

(4) Sejauhmanakah pengaruh pesan komunikasi saat chatting di internet terhadap persahabatan mahasiswa di dunia maya?

(5) Sejauhmanakah pengaruh intensitas chatting, daya tarik chatting, ketergantungan melakukan chatting, dan pesan komunikasi pada saat chatting di internet secara bersamaan terhadap persahabatan mahasiswa di dunia maya?

\subsection{Tujuan Penelitian}

Penelitian ini bertujuan:

(1) Untuk menemukan pengetahuan tentang pengaruh intensitas chatting di internet terhadap persahabatan mahasiswa di dunia maya.

(2) Untuk menemukan pengetahuan tentang daya tarik chatting di internet terhadap persahabatan mahasiswa di dunia maya.

(3) Untuk menemukan pengetahuan tentang ketergantungan melakukan chatting di internet berpengaruh terhadap persahabatan mahasiswa di dunia maya.

(4) Untuk menemukan pengetahuan tentang pesan komunikasi saat chatting di internet terhadap persahabatan mahasiswa di dunia maya.

(5) Untuk menemukan pengetahuan konsep baru dan model tentang intensitas chatting, daya tarik chatting, ketergantungan melakukan chatting, dan pesan komunikasi pada saat chatting di internet secara bersamaan terhadap persahabatan mahasiswa di dunia maya.

\subsection{Kerangka Pemikiran}

Secara makro, penelitian ini dilihat dari perspektif teori struktural fungsional yang berasal dari Comte dalam menelaah struktur dan dinamika sosial. Teori ini mengasumsikan bahwa "masyarakat dapat dilihat sebagai sistem yang terdiri dari bagian-bagian yang memiliki fungsi dan saling tergantung satu dengan yang lain. Jika bagian-bagian sistem berfungsi, maka akan dicapai keadaan normal (equilibrium), jika sebaliknya yang terjadi, maka akan berkembang keadaan patologis, sehingga terjadi ketidakseimbangan yang akan menimbulkan perubahan sosial" (lihat Poloma, 2000:25). Pemikiran Comte dikembangkan oleh Spencer yang mendapat dukungan dari sosiolog terkenal Durkheim. Pandangan Durkheim berkembang di Eropa dan di Amerika. Di Amerika, pemikiran Durkheim dikembangkan oleh Parsons. Selanjutnya, pemikiran Parsons dikembangkan oleh Merton yang mengemukakan pandangan tentang fungsi dan disfungsi komunikasi (media massa). Menurut Merton, "media komunikasi itu memiliki fungsi dan disfungsi bagi masyarakat" (dalam Wright, 1985:9).

Chatting di internet sebagai bentuk komunikasi antarpribadi baru tidak lepas dari perkembangan pesat yang terjadi dalam teknologi komunikasi yang baru. Internet sendiri merupakan bagian dari perkembangan yang berjalan cepat dalam bidang teknologi pada umumnya, yang memengaruhi kehidupan manusia secara sosial. Kehadiran internet telah mengubah banyak segi kehidupan manusia, termasuk dalam bagaimana cara orang berkomunikasi dan bagaimana memperoleh teman atau sahabat.

Dilihat dari perspektif teori strukturalfungsional, teknologi komunikasi yang menyebar dan digunakan masyarakat dapat dipahami sebagai bagian dari perubahan sosial yang dampaknya dapat mengganggu keseimbangan. Respons masyarakat, positifmaupun negatif, akhirnya akan mengarah pada perubahan sosial dan dicapainya kembali keseimbangan di tengah masyarakat.

Secara messo, masalah penelitian dilihat dari Teori Kehadiran Sosial (Social Presence Theory). Teori ini menjelaskan setiap media komunikasi memiliki derajat kehadiran yang berbeda. Komunikasi tatap-muka (face-to-face) memiliki derajat kehadiran paling tinggi, sedangkan komunikasi tertulis berupa teks tingkat kehadirannya lebih rendah karena tingkat interaktivitasnya rendah. Surat elektronik (e-mail) termasuk yang digolongkan ke dalam bentuk komunikasi yang tingkat kehadirannya rendah (Short et al., 1976). Karena komunikasi antarpribadi melalui chatting bersifat teks, maka berdasarkan 
perspektif teori ini tingkat interaktivitas dan kehadirannya juga rendah. ${ }^{2}$

Namun demikian, berdasarkan teori hyperpersonal yang dijadikan teori operasional penelitian ini, komunikasi antarpribadi bermedia internet seperti yang dilakukan melalui chatting memiliki kekhususan terutama karena perkembangan teknologi komputer baik perangkat keras maupun lunaknya, sehingga dalam chatting misalnya, para pengguna dapat meningkatkan efektivitas pesan komunikasi dengan mendayagunakan emoticon untuk membantu mengekspresikan perasaan serta teks dan grafis sehingga efektivitasnya dapat mengimbangi komunikasi yang diselenggarakan secara tatapmuka (Walther dalam Baldwin, et al., 2004:247).

Komunikasi antarpribadi, menurut Knapp dan Miller (1994:8), meliputi “interaksi tatap muka, di mana komunikator secara fisik berdekatan. Interaksi melalui telepon, komputer, dan teknologi yang lainnya adalah bagian yang dipelajari juga dalam komunikasi antarpribadi”.

Komunikasi antarpribadi tatap muka menurut Pearson (dalam Sendjaja, 1994:41) memiliki enam karakteristik, yaitu: dimulai dengan diri pribadi (self), bersifat transaksional, mencakup isi pesan dan hubungan antarpribadi, adanya kedekatan fisik antara pihak yang berkomunikasi, tidak dapat diubah maupun diulang. Sedangkan dalam mengembangkan hubungan antarpribadi terdapat lima faktor utama yang memengaruhinya, yaitu: daya tarik (fisik dan kepribadian), kedekatan (proksimitas), pengukuhan, kesamaan, sifat saling melengkapi (DeVito, 1997:238).

Adapun pengertian komunikasi antarpribadi bermedia internet, menurut Pixy Ferris, yaitu "interaksi antarpribadi yang dihubungkan oleh komputer, yang meliputi komunikasi asynchonous dan synchronous melalui fasilitas di internet". Komunikasi asynchronous adalah komunikasi melalui media internet di mana pengirim dan penerima pesan dalam berinteraksi tidak berada pada tempat dan waktu yang sama, pesan tetap sampai kepada sasaran yang dituju. Sedangkan synchronous adalah komunikasi melalui Internet dengan interaksi yang bersamaan waktunya.
Karakteristik komunikasi antarpribadi bermedia, internet, menurut McKenna \& Bargh (2000) dan Kiesler \& Sproull (1992), yaitu interaksi langsung secara simultan, komunikasi tertulis, komunikasi bersifat anonim, hubungan antarpribadi terbentuk berdasarkan minat, tidak ada hambatan fisik dan psikis, penggunaan isyarat tekstual untuk mengatasi keterbatasan nonverbal (isyarat visual dan aural).

Komunikasi antarpribadi bermedia internet merupakan salah satu kemajuan yang dicapai dalam teknologi komunikasi baru. Menurut Baldwin et al. (2004:246), teknologi komunikasi baru didefinisikan sebagai "metode baru dalam penyimpanan, penyampaian, dan penerimaan informasi yang meliputi bentuk informasi apa pun dari teknologi digital seperti World Wide Web, chatrooms, bahkan radio dan televisi satelit".

Menurut para peneliti komunikasi bermedia, komputer digunakan baik untuk berkomunikasi antarpribadi maupun komunikasi massa, sehingga komunikasi bermedia komputer mampu mengubah fungsi komunikasi massa yang telah ada. Dengan menambah empat fungsi media massa, yaitu: menginformasikan, menjelaskan, menghibur, dan transmisi budaya, komunikasi bermedia komputer secara mendasar digunakan untuk interaksi sosial (Baldwin et al., 2004:248).

Penelitian ini memokuskan pada komunikasi antarpribadi menggunakan fasilitas chat di internet. Chatting merupakan komunikasi interaktif, karena sifatnya yang dialogis dan umpan balik, yang diterima bersifat langsung. Seseorang dapat mengetahui tanggapan teman chatting segera ketika komunikasi berlangsung. Komunikasi yang dilakukan berupa tulisan yang diketik lewat keyboard lalu muncul di layar monitor komputer. Komunikasi bermedia internet menggunakan fasilitas chat dalam penelitian ini ditelaah dari intensitas chatting, daya tarik chatting, ketergantungan melakukan chatting, dan pesan komunikasi pada saat chatting yang diuraikan berikut.

\section{1) Intensitas Chatting}

Intensitas chatting adalah berapa sering dan berapa lama waktu yang digunakan seseorang 
untuk melakukan chatting. Menurut Quitter (1994), "komunikasi bermedia internet membuat orang terpikat untuk berkomunikasi secara intensif, terusmenerus." (Quitter dalam Nguyen dan Alexander, 1998:103).

Berdasarkan pendapat Quitter tersebut berarti orang berkomunikasi menggunakan internet dengan frekuensi tertentu, sehingga menghabiskan sejumlah waktu tertentu pula untuk menggunakannya. Menurut Clane et al., 1984 (dalam Tubbs dan Moss, 1996:199), "waktu dibutuhkan bagi semua kualitas suatu hubungan, dalam hubungan apa pun, agar hubungan tersebut berkembang". Selain itu, hubungan antarpribadi yang kuat, menurut Haythornthwaite (2000), ditentukan oleh "frekuensi berinteraksi, keintiman, pengungkapan diri, jenis pertukaran, kontak secara tatap muka, keinginan untuk berdekatan”.

Mengenai jumlah waktu penggunaan internet oleh para penggunanya, hasil riset yang dilakukan oleh Swa-Mark Plus \& Co. (dalam Abrar, 2003: 7980 ), menyebutkan terdapat tiga kelompok pengguna internet berdasarkan lama waktu yang dipakainya, yaitu: pengguna berat/heavy users (lebih dari 40 jam perbulan); pengguna sedang/ medium user (10 - 40 jam perbulan); dan pengguna ringan /light user (tidak lebih dari 10 jam perbulan).

Melihat hasil penelitian tersebut banyak waktu seseorang menggunakan internet masuk dalam kategori pengguna ringan, sedang, dan berat. Merujuk pada hasil penelitian tersebut, dalam penelitian ini ditelaah bagaimana intensitas komunikasi antarpribadi pengguna dengan menggunakan fasilitas chat di internet.

\section{2) Daya Tarik Chatting}

Melalui fasilitas chat sebagai salah satu fasilitas yang memiliki daya tarik di internet, pengguna dapat melakukan percakapan mengenai topik pembicaraan tertentu dalam satu waktu yang sebenarnya (Sidharta, 1996:153). Penggunaan fasilitas chat ini dapat dilihat dari segi penggunaan nama samaran dan sistem menu, yaitu menu yang digunakan dalam program chat seperti : suara, dan emoticons (Sidharta, 1996: 153).

Menurut Fudpucker (1992) emoticon adalah icon (lambang) atau gambar untuk mengekspresikan perasaan pada saat chatting (Fudpucker dalam Shields, 1998:65). Sebagai contoh, penggunaan lambang untuk melengkapi ekspresi kata-kata dalam chatting, seperti “... kalau tertawa mengetik J, atau bila ragu-ragu dengan menulis: CCC, atau tidak suka dengan menulis simbol $<<$. Dalam chatting, juga dapat menggunakan singkatan tertentu agar dapat mengetahui keadaan lawan chatting. Misalnya, untuk menanyakan identitas diajukan kode $a s l$, yang artinya age (usia), sex (jenis kelamin), dan location (tempat)".

Dengan demikian, saat chatting pengguna selain dapat mengekpresikan pikiran dan perasaan dengan kata-kata, juga dapat melengkapi katakatanya dengan simbol dan singkatan yang dapat memberi kemudahan dalam berkomunikasi.

\section{3) Ketergantungan Melakukan Chatting}

Dengan teknologi komunikasi seorang chatter dapat terus berhubungan dengan chatter lain tanpa terhalang oleh jarak dan waktu. Chatting tidak hanya untuk bertukar informasi, melainkan menjadi ajang pergaulan kaum muda dan bisa menambah cakrawala tentang dunia di seputarnya. Menurut majalah Yahoo (November 2001) yang dikutip oleh Kurnia, "pengguna internet yang keranjingan ngobrol (chatting) di internet mencapai 60-70 juta pengguna". ${ }^{5}$

Menurut Anderson (2002), penelitian bertema ketergantungan terhadap internet telah banyak dilakukan di beberapa negara. Ahli psikologi menyatakan "karakteristik seseorang yang mengalami ketergantungan terhadap Internet memiliki kedekatan dengan pathological gambling". Fenomena itu oleh Anderson dinamakan internet addiction, internet dependence, atau pathological internet use. ${ }^{6}$ Untuk mengetahui faktor apa yang menyebabkan seseorang menjadi tergantung menggunakan internet secara berlebihan adalah "accessibility, kesulitan membina hubungan di dunia nyata, dan jenis kepribadian seseorang" (Kandell, 1998, dalam Anderson). ${ }^{7}$

Sebenarnya, melakukan chatting di internet bukanlah suatu aktivitas yang dapat menimbulkan ketergantungan. Young \& Rodgers $(1996)^{8}$ mengungkapkan kriteria untuk mendeteksi orang 
yang mengalami ketergantungan internet, khususnya dalam melakukan chatting. Dari sepuluh kriteria, seseorang disebut mengalami ketergantungan apabila paling sedikit terpenuhi empat atau lebih dari kriteria yang diajukan, yaitu :

(1) Merasa asyik dengan internet

(2) Menambah waktu menggunakan internet dari yang direncanakan.

(3) Tidak mampu mengontrol penggunaan internet.

(4) Merasa gundah ketika mengurangi atau menghentikan penggunaan internet.

(5) Menggunakan internet sebagai cara melarikan diri dari masalah.

(6) Berbohong untuk menyembunyikan keterlibatannya menggunakan internet.

(7) Menempuh resiko kehilangan hubungan, pekerjaan, pendidikan, atau kesempatan karier, karena internet.

(8) Tetap menggunakan internet walaupun telah menghabiskan uang untuk online.

(9) Teringat internet ketika offline.

(10) Menggunakan internet lebih lama dari waktu yang direncanakan.

Berdasarkan kriteria dari Young tersebut, penelitian ini bermaksud menelaah aktivitas pengguna melakukan chatting. Demikian beberapa aspek yang hendak diungkap dalam ketergantungan melakukan chatting.

\section{4) Pesan Komunikasi pada Saat Chatting}

Pesan komunikasi pada saat chatting ditelaah dari keragaman dan kedalaman pesan. Karena dalam pembinaan hubungan antarpribadi pesan yang disampaikan para chatter tidak selalu dipertukarkan secara seimbang. Menurut Tubbs dan Moss (1996:201) seberapa banyak informasi yang dimiliki bersama dalam suatu hubungan dapat dilihat berdasarkan keluasan dan kedalaman. Keluasan menunjukkan variasi topik yang dikomunikasikan. Sedangkan kedalaman merujuk pada keintiman apa yang dikomunikasikan. Beberapa aspek tertentu hubungan memengaruhi bagaimana keluasan dan kedalaman komunikasi yang dilakukan, yakni apakah masing-masing akan terus berbicara secara dangkal atau memulai penyingkapan diri.

Dalam mempelajari komunikasi antarpribadi, dibedakan antara isi pesan dan hubungan antara pihak-pihak yang berkomunikasi. Setiap pesan mengandung isi, terlepas dari apakah informasinya benar atau salah. Pesan juga mendefinisikan bagaimana ia harus ditafsirkan, dan sebagai konsekuensinya juga sesuatu tentang hubungan antara orang-orang yang terlibat.

Dalam berkomunikasi melalui fasilitas chat yang dilakukan oleh seseorang kepada teman chatting tidak hanya mempertukarkan pesan, melainkan juga menyampaikan pesan yang menunjukkan bagaimana ia mempersepsi orang lain, dan bentuk hubungan apa yang mereka bina. Bentuk pesan dalam komunikasi bermedia internet, menurut Van Dijk (1999: 206), berupa, "teks, suara, dan data, sehingga dapat membuka saluran komunikasi yang lebih luas". Pada bagian lain, Van Dijk (1999:213) mengutip pendapat Spears dan Lea mengenai apa yang menjadi ukuran dalam menyusun percakapan di internet yaitu, "ditentukan oleh konteks yang khusus, meliputi bahasa yang tidak formal, dan etika berkomunikasi yang disebut netiquette".

\section{5) Persahabatan di Dunia Maya}

Persahabatan di dunia maya yang dilakukan para pengguna internet sebagai salah satu bentuk hubungan antarpribadi dalam komunitas cyber mengacu pada teori komunikasi antarpribadi yang dikemukakan DeVito (1997: 259), yaitu "hubungan dalam persahabatan merupakan bagian dari teori komunikasi antarpribadi. Dalam mengembangkan hubungan ditentukan, antara lain, oleh karakteristik dan tahap hubungan antarpribadi”. Teori yang dikemukakan DeVito tersebut menjadi teori operasional dalam penelitian ini.

DeVito (2001: 252) menyebutkan, "ketika seseorang menggunakan internet, aktivitas yang dilakukan antara lain untuk mencari teman baru (kenalan), dan menjalin hubungan secara online. Terbentuknya hubungan antarpribadi di dunia maya (online interpersonal relationships) ini seiring dengan meningkatnya jumlah pengguna internet".

Seorang sahabat merupakan seseorang yang mempunyai kedudukan tertentu dalam hubungan 
antarpribadi. Persahabatan di dunia maya adalah salah satu jenis hubungan yang dijalin oleh seseorang dalam komunitas cyber. Demikian pentingnya hubungan di internet ini, Strangelove (dalam Sofyan, 2003:16) mengungkapkan, "internet bukanlah teknologi, ia bukan pula tentang informasi, tetapi ia adalah komunikasi. Dari komunikasi itulah tumbuh berbagai hubunganhubungan yang sudah maupun yang tak terduga sejak awal".

Jika timbul pertanyaan apa sebenarnya arti sahabat dalam komunitas cyber? DeVito(2001:335) menjelaskan persahabatan adalah "hubungan antarpribadi antara dua orang yang saling menghasilkan penghargaan secara positif". Menurut Reisman ( dalam DeVito, 2001:336), “tipe ideal persahabatan adalah reciprocity yang memiliki ciri kesetiaan, pengorbanan, saling merasakan, dan memberi. Tipe ini didasarkan pada kesamaan, setiap individu sama-sama berbagi dalam memberi, menerima keuntungan dan penghargaan dalam hubungan".

William Rawlins mengemukakan teori persahabatan yang dialektis (dalam Littlejohn, 1999: 268) bahwa :

Persahabatan dalam tahap manapun dari kehidupan menampilkan sekumpulan tantangan yang menarik dan seringkali kompleks. Tantangan dalam persahabatan terutama muncul dari kebutuhan untuk menangani berbagai kontradiksi atau dialektik. Dialektik didefinisikan sebagai suatu ketegangan antara pihak-pihak yang bertentangan dalam sebuah sistem yang menuntut penyelesaian.

\section{Gambar 1: Kerangka Pemikiran}

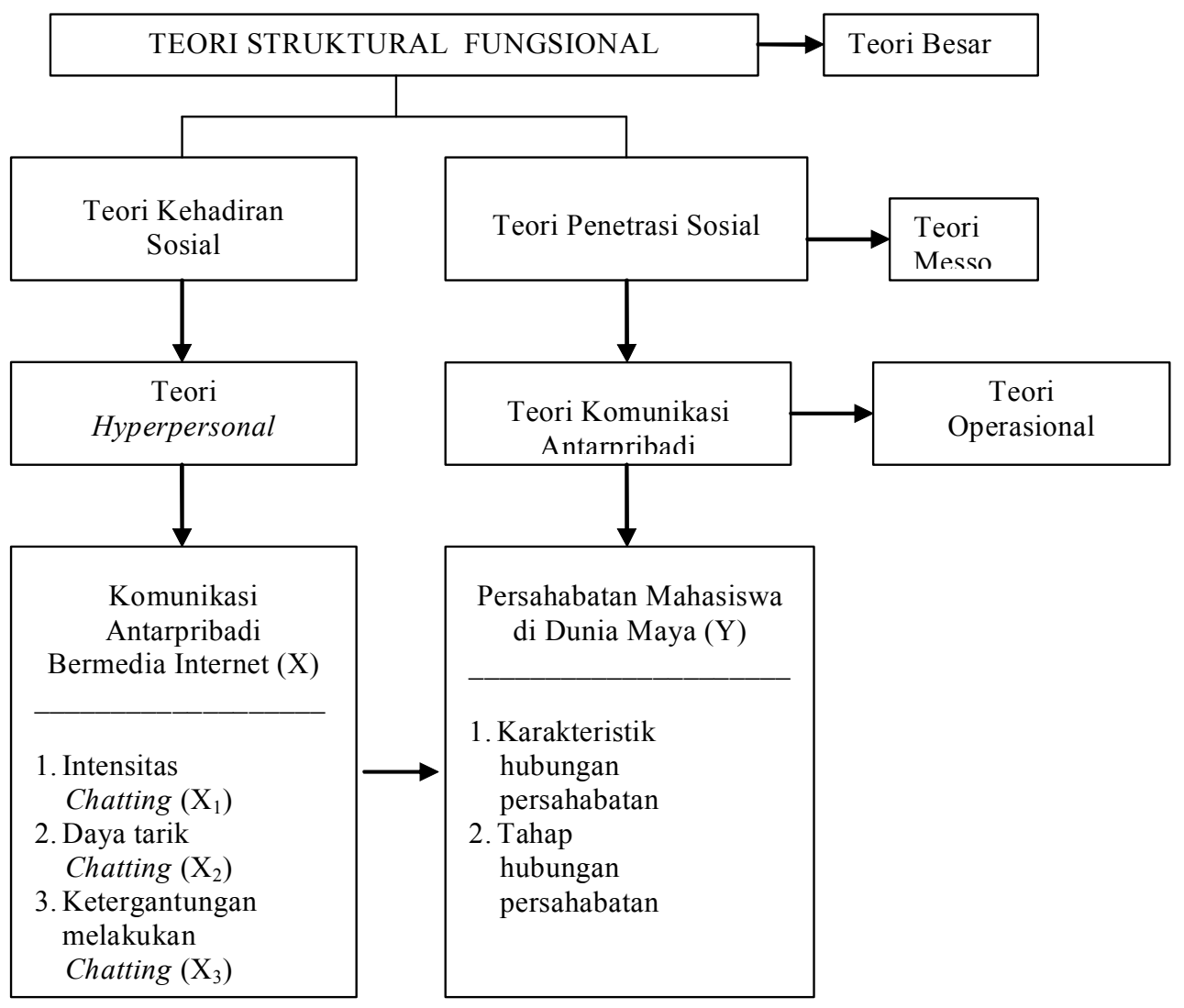


Berdasarkan penjelasan tersebut persahabatan membentuk sebuah konteks yang unik dan menarik di mana hubungan berkembang. Bagi sebagian orang, sahabat dapat berarti orang yang bisa dipercaya dan diandalkan. Menurut Hortacsu dalam risetnya yang berjudul Target Communication During Adolesence, mengemukakan bahwa bersahabat adalah berbagi minat, beban pikiran, perasaan, dan juga rahasia. ${ }^{9}$

Untuk mengetahui bagaimana persahabatan sebagai salah satu bentuk hubungan antarpribadi dalam komunitas cyber, DeVito (1997: 259) menjelaskan tentang hubungan antarpribadi bahwa, "dalam mengembangkan hubungan, salah satu faktor yang penting karakteristik hubungan antarpribadi. Selain itu, hubungan antarpribadi ini dapat berlangsung melalui beberapa tahap, mulai dari tahap interaksi awal sampai ke pemutusan (dissolution)".

Dalam menjalin persahabatan di dunia maya para chatter dituntut memiliki kemampuan membangun hubungan baik di antara mereka. Dalam mewujudkan hubungan baik tersebut, DeVito (1997:259) menekankan pada "keterbukaan (openness), empati (empathy), sikap mendukung (supportiveness), sikap positif (positiveness), dan kesetaraan (equality)

Hubungan antarpribadi yang akrab tidak segera terjadi setelah pertemuan berlangsung pada saat chatting. Keakraban yang tumbuh di antara para chatter cenderung berlangsung secara bertahap, melalui serangkaian langkah atau tahap. Menurut Knapp, 1984, dan Wood, 1982 (dalam DeVito, 1997:233), "kebanyakan hubungan berkembang melalui tahap-tahap pengembangan hubungan yang mencakup: kontak, keterlibatan, keakraban, perusakan, dan pemutusan.

Berdasarkan uraian tersebut komunikasi antarpribadi bermedia internet, dalam hal ini chatting, memiliki potensi untuk menimbulkan pengaruh yang positif maupun negatif dalam interaksi manusia termasuk dalam persahabatan. Berbagai teori yang berkaitan dengan variabelvariabel penelitian, baik yang berkenaan dengan komunikasi antarpribadi bermedia internet (variabel bebas) maupun persahabatan di dunia maya (variabel terikat), semuanya dirangkum dalam gambar visual berupa kerangka pemikiran yang memperlihatkan pertalian variabel-variabel penelitian ini.

\subsection{Hipotesis}

Berdasarkan kerangka pemikiran tersebut, dirumuskan hipotesis berikut :

(1) Semakin tinggi pengaruh intensitas chatting di internet maka semakin erat persahabatan mahasiswa di dunia maya.

(2) Semakin tinggi pengaruh daya tarik chatting di internet maka semakin erat persahabatan mahasiswa di dunia maya.

(3) Semakin tinggi pengaruh ketergantungan melakukan chatting di internet maka semakin erat persahabatan mahasiswa di dunia maya.

(4) Semakin tinggi pengaruh pesan chatting di internet maka semakin erat persahabatan mahasiswa di dunia maya.

(5) Semakin tinggi pengaruh intensitas chatting, daya tarik chatting, ketergantungan melakukan chatting, dan pesan komunikasi pada saat chatting secara bersamaan maka semakin erat persahabatan mahasiswa di dunia maya.

\subsection{Metode Penelitian}

Pendekatan penelitian ini kuantitatif dengan menggunakan metode survei eksplanatoris, yaitu "suatu penelitian yang bertujuan menguji hipotesis dengan cara mendasarkan pada pengamatan terhadap akibat yang terjadi dan mencari faktorfaktor yang mungkin menjadi penyebab melalui data tertentu" (Rusidi, 1989:19). Objek penelitian ini adalah mahasiswa pengguna fasilitas Chat yang mengakses internet di Kubus Net Bandung, tempat pelayanan internet terbesar di kota Bandung yang memiliki 4 lokasi/cabang. Pengguna internet di tempat ini sebanyak 1025 orang perhari. ${ }^{10}$

Jumlah pengguna fasilitas chat yang berstatus mahasiswa di Kubus Net tidak tersedia secara lengkap, maka teknik pengambilan sampling-nya menggunakan sampling klaster dua tahap dengan 
menganggap lokasi/cabang tempat penyewaan internet sebagai klaster. Berdasarkan teknik pergambilan sampling tersebut jumlah mahasiswa pengguna internet yang menjadi sampling penelitian, sebanyak 265 orang. Sedangkan teknik pengumpulan data dilakukan dengan kuesioner, wawancara, observasi, studi kepustakaan, dan dokumentasi.

Data penelitian ini berupa data kualitatif dan data kuantitatif. Data kualitatif diperoleh dari hasil wawancara yang disusun melalui reduksi data, penyajian data, dan penarikan kesimpulan. Adapun data kuantitatif dianalisis dengan menggunakan analisis statistik deskriptif dan inferensial. Statistik deskriptif ini terdiri dari distribusi frekuensi dan persentase yang disajikan dalam bentuk tabel tunggal maupun tabel silang. Statistik inferensial yang digunakan untuk menguji hipotesis, yaitu analisis jalur (Sitepu, 1994 : 130). Selanjutnya, dengan menggunakan analisis korelasi dapat diketahui besarnya hubungan variabel penyebab dengan variabel akibat.

\section{Hasil Penelitian dan Pembahasan}

Komunikasi antarpribadi bermedia internet diukur dalam empat variabel, terdiri dari intensitas chatting $\left(\mathrm{X}_{1}\right)$, daya tarik chatting $\left(\mathrm{X}_{2}\right)$, ketergantungan melakukan chatting $\left(\mathrm{X}_{3}\right)$ dan pesan komunikasi saat chatting di internet $\left(\mathrm{X}_{4}\right)$ sebagai variabel sebab (variabel eksogenus), dan persahabatan mahasiswa di dunia maya (Y) sebagai variabel akibat (variabel endogenus). Berdasarkan hipotesis penelitian, hasil perhitungan pengaruh variabel bebas (X) terhadap variabel terikat $(\mathrm{Y})$ tergambar dalam diagram berikut.

Bagan di atas menjelaskan koefisien jalur secara parsial intensitas chatting terhadap persahabatan mahasiswa di dunia maya $\left(\mathrm{r}_{\mathrm{YX} 1}\right)$ sebesar 0,292 dengan t-hitung sebesar 3,754, koefisien jalur secara parsial antara daya tarik chatting terhadap persahabatan mahasiswa di dunia maya $\left(\mathrm{r}_{\mathrm{YX} 2}\right)$ sebesar 0,195 dengan t-hitung sebesar 2,437 , koefisien jalur secara parsial ketergantungan melakukan chatting terhadap persahabatan mahasiswa di dunia maya $\left(\mathrm{r}_{\mathrm{YX} 3}\right)$ sebesar 0,229 dengan t-hitung sebesar 3,117 dan koefisien jalur secara parsial antara pesan komunikasi saat chatting di internet terhadap persahabatan mahasiswa di dunia maya $\left(\mathrm{r}_{\mathrm{YX} 4}\right)$ sebesar 0,331 dengan t-hitung sebesar 4,564. Dari perhitungan di atas diketahui koefisien jalur variabel lain ( e) Pye sebesar 0,740.

Untuk mengetahui pengaruh variabel bebas

\section{Gambar 2: Path Diagram Model Persamaan Struktural Pengaruh Komunikasi Antarpribadi Bermedia Internet terhadap Persahabatan Mahasiswa di Dunia Maya}

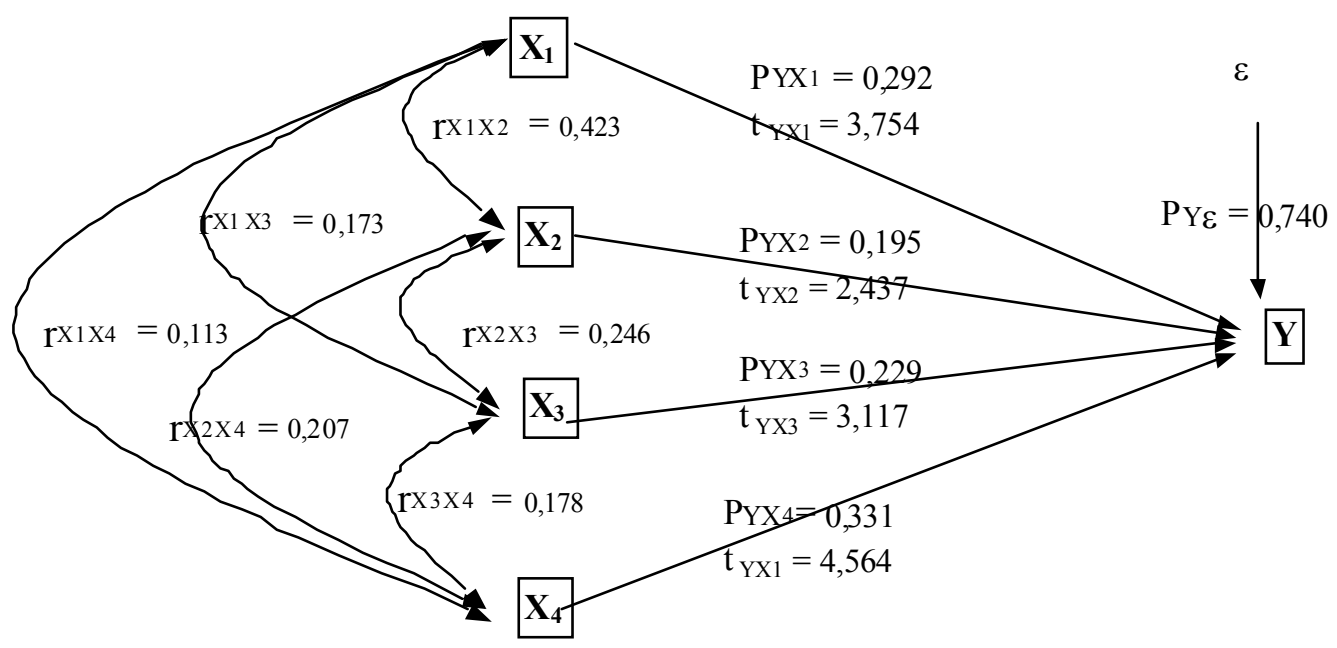


terhadap variabel tak bebas, dilakukan pengujian atas hasil analisis jalur menggunakan uji $F$ dan Uji $\mathrm{T}$ dengan membandingkan nilai $\mathrm{f}$ dan $\mathrm{t}$ hitung dengan nilai $f$ dan $t$ tabel. Untuk a penelitian sebesar 0,05, batas dinyatakan uji signifikan untuk uji simultan adalah $\mathrm{F}_{\text {tabel }}$ dengan derajat bebas $\mathrm{db}_{1}$ $=4$ dan $\mathrm{db}_{2}=111$ sebesar 2,453 dan untuk batas dinyatakan uji signifikan pada uji parsial adalah $\mathrm{t}_{\text {tabel }}$ dengan derajat bebas $\mathrm{db}=111$ sebesar 1,659.

Dilihat dari nilai $\mathrm{F}_{\text {hitung }}$ diperoleh sebesar 22,977 dengan nilai sig. sebesar 0,000 (sangat kecil). Karena $\mathrm{F}_{\text {hitung }}$ lebih besar dari $\mathrm{F}_{\text {tabel }}$ maka $\mathrm{H}_{0}$ ditolak, dan hipotesis alternatif diterima. Berdasarkan uji $\mathrm{F}$, dapat disimpulkan bahwa terdapat pengaruh secara bersamaan komunikasi antarpribadi bermedia internet yang terdiri atas intensitas chatting $\left(\mathrm{X}_{1}\right)$, daya tarik chatting $\left(\mathrm{X}_{2}\right)$, ketergantungan melakukan chatting $\left(\mathrm{X}_{3}\right)$ dan pesan komunikasi saat chatting di internet $\left(\mathrm{X}_{4}\right)$ terhadap persahabatan mahasiswa di dunia maya. Hasil perhitungan path analysis, selain untuk menguji pengaruh variabel bebas secara bersamaan, juga menyediakan informasi untuk dilakukan uji hubungan secara parsial masing-masing variabel yang terdapat dalam variabel $\mathrm{X}$ dengan variabel $\mathrm{Y}$ yang disajikan pada tabel berikut.

Hasil penelitian menunjukkan komunikasi antarpribadi bermedia internet berpengaruh secara signifikan terhadap persahabatan mahasiswa di dunia maya, yang mendukung perspektif struktural fungsional, di mana pengaruh yang diperoleh bersifat fungsional dan disfungsional.

Pengaruh fungsional, komunikasi antarpribadi melalui chat di internet memadukan kebutuhan untuk berhubungan secara sosial dengan media komunikasi yang berkembang pesat melalui internet. Pengguna berkomunikasi antarpribadi melalui fasilitas chat tidak secara global (lokal), dan anonimitas komunikasi antarpribadi melalui chat di internet meningkatkan kemampuan berekspresi yang menambah keluasan dan kedalaman pesan. Di sisi lain, anonimitas melonggarkan kendali sosial dalam komunikasi antarpribadi di dunia maya yang membuka peluang

Tabel 1

Uji Hipotesis Pengaruh secara Parsial

\begin{tabular}{|l|l|l|l|l|l|l|}
\hline No & \multicolumn{1}{|c|}{ Hipotesis } & $\begin{array}{l}\text { Koefi- } \\
\text { sien } \\
\text { Jalur }\end{array}$ & p-value & $\mathbf{t}_{\text {hitung }}$ & $\mathbf{t}_{\text {tabel }}$ & $\begin{array}{l}\text { Kesim- } \\
\text { pulan } \\
\text { Statistik }\end{array}$ \\
\hline 1 & $\begin{array}{l}\text { Semakin tinggi pengaruh intensitas } \\
\text { chatting di internet maka semakin } \\
\text { erat persahabatan di dunia maya }\end{array}$ & 0.292 & 0.000 & 3.754 & 1,659 & $\begin{array}{l}\text { Signifikan } \\
\left(\mathrm{H}_{0} \text { ditolak }\right)\end{array}$ \\
\hline 2 & $\begin{array}{l}\text { Semakin tinggi pengaruh daya } \\
\text { tarik chatting di internet maka } \\
\text { semakin erat persahabatan di dunia } \\
\text { maya }\end{array}$ & 0.195 & 0.016 & 2.437 & 1,659 & $\begin{array}{l}\text { Signifikan } \\
\left(\mathrm{H}_{0} \text { ditolak }\right)\end{array}$ \\
\hline 3 & $\begin{array}{l}\text { Semakin tinggi pengaruh } \\
\text { ketergantungan melakukan } \\
\text { chatting di internet maka semakin } \\
\text { erat persahabatan di dunia maya }\end{array}$ & 0.229 & 0.002 & 3.117 & 1,659 & $\begin{array}{l}\text { Signifikan } \\
\left(\mathrm{H}_{0} \text { ditolak }\right)\end{array}$ \\
\hline 4 & $\begin{array}{l}\text { Semakin tinggi pengaruh pesan } \\
\text { komunikasi saat chatting di } \\
\text { internet maka semakin erat } \\
\text { persahabatan di dunia maya }\end{array}$ & 0.331 & 0.000 & 4.564 & 1,659 & $\begin{array}{l}\text { Signifikan } \\
\left(\mathrm{H}_{0} \text { ditolak }\right)\end{array}$ \\
\hline
\end{tabular}

Sumber: Data hasil penelitian 2005 yang telah diolah 
Tabel 2

Variabel X terhadap Variabel Y

\begin{tabular}{|c|l|c|}
\hline No & \multicolumn{1}{|c|}{ Pengaruh X terhadap Y } & Persentase \\
\hline \hline 1 & Pengaruh Total $\mathrm{X}_{1}$ terhadap $\mathrm{Y}$ & $13,2 \%$ \\
\hline 2 & Pengaruh Total $\mathrm{X}_{2}$ terhadap Y & $8,6 \%$ \\
\hline 3 & Pengaruh Total $\mathrm{X}_{3}$ terhadap $\mathrm{Y}$ & $8,8 \%$ \\
\hline 4 & Pengaruh Total $\mathrm{X}_{4}$ terhadap $\mathrm{Y}$ & $14,7 \%$ \\
\hline 5 & Total Pengaruh Variabel X terhadap $\mathrm{Y}$ & $45,3 \%$ \\
\hline 6 & Pengaruh Variabel Lain $(\varepsilon)$ & $54,7 \%$ \\
\hline \multicolumn{2}{|c|}{ Jumlah } & $100,0 \%$ \\
\hline
\end{tabular}

tumbuhnya komunikasi semu yang disfungsional. Persahabatan di dunia maya (online friendship) melalui komunikasi antarpribadi bermedia Internet merupakan kelengkapan dari persahabatan yang telah ada, karena pelakunya melakukan juga persahabatan tatap-muka.

Total pengaruh komunikasi antarpribadi bermedia internet terhadap persahabatan mahasiswa di dunia maya sebesar 45,3\%, sedangkan variabel lain yang memengaruhi persahabatan di dunia maya sebesar $54,7 \%$ seperti terlihat dalam tabel 2.

Pengujian statistik menunjukkan "intensitas chatting di internet" berpengaruh terhadap persahabatan mahasiswa di dunia maya, total pengaruhnya adalah 13,2 \%. Data penelitian memperlihatkan mayoritas responden masuk pada kategori pengguna ringan (Abrar, 2003: 79-80), karena menggunakan internet selama kurang dari 4 jam sampai 8 jam perbulan.

Menurut Quitter (1994), orang berkomunikasi melalui internet karena daya tarik media tersebut (dalam Nguyen \& Alexander, 1998:103). Responden berkomunikasi antarpribadi di dunia maya, antara lain, untuk memecahkan masalah dalam perkuliahan, memperoleh pekerjaan, dan memenuhi kebutuhan memelihara hubungan di dunia maya.

Hasil pengujian statistik menunjukkan "daya tarik chatting" di internet berpengaruh terhadap persahabatan mahasiswa di dunia maya, total pengaruh yang diperoleh 8,6 persen. Menurut responden komunikasi antarpribadi melalui memiliki daya tarik yang cukup tinggi. Daya tarik internet menurut responden, antara lain, karena chat room lokal (satu kota), penggunaan nama samaran, sistem menu dan emoticon, memperoleh teman dunia maya, serta kecepatan proses mengirim dan menerima pesan (Sidharta, 1996 : 142; Bechar-Israeli, 2004; Sopyan, 2003:21, Shields, 1998: 65).

Komunikasi di internet dapat bersifat anonim karena bisa menggunakan nama samaran, penelitian ini mengungkapkan responden sering berperan menjadi orang lain ketika chatting, dan dapat menyembunyikan identitas yang sesungguhnya (Sopyan, 2003:24; Bromberg dalam Shields, 1998 : 143; Rheingold, 1998:148). Di lain pihak, anonimitas bisa memberi jaminan akan rasa aman kepada chatter dalam berkomunikasi antarpribadi di internet. Karena hal tersebut, pengguna menjadi lebih terbuka dalam mengekspresikan diri(Van Dijk, 1999:218).

Hasil pengujian statistik juga menunjukkan "ketergantungan melakukan chatting" di internet berpengaruh terhadap persahabatan mahasiswa di dunia maya. Total pengaruhnya 8,8 persen. 
Hasil penelitian menunjukkan responden mengalami ketergantungan yang ringan dalam melakukan chatting di internet. Hal ini terlihat pada aktivitas responden yang jarang mengisi waktu luang dengan melakukan chatting, jarang teringat chatting saat melakukan aktivitas lain, tidak menambah waktu chatting. Tetapi di sisi lain waktu untuk melakukan chatting kurang terkontrol, dan sebagian responden mengalami perasaan gelisah ketika harus mengurangi chatting. Menurut kriteria ketergantungan terhadap internet dari Young \& Rodgers (1998) ${ }^{11}$, responden penelitian ini masuk pada kategori yang ringan.

Hasil pengujian statistik menunjukkan "pesan komunikasi saat chatting" di internet berpengaruh terhadap persahabatan mahasiswa di dunia maya, total pengaruhnya adalah 14,7 persen. Hasil penelitian menunjukkan mayoritas responden menyatakan pesan komunikasi saat chatting dengan kenalan, teman di dunia maya beragam dan mendalam. Pembicaraan mereka berkaitan dengan berbagai topik yang dibahas, antara lain, tentang perkuliahan, keadaan cuaca, peristiwa aktual, hobi, dan sebagainya.

Pesan chatting dengan kenalan baru berlangsung secara sepintas lalu, sedangkan dengan sahabat di dunia maya dilakukan secara mendalam. Responden memandang chatting sama berartinya dengan berbincang di dunia nyata. Dalam membina persahabatan di dunia maya, responden bersifat terbuka, empatik, suportif, positif, dan setara (Rakhmat, 1996:130, DeVito, 1997:259-261). Selain itu, responden menggunakan bahasa yang tidak resmi atau bahasa nonformal saat chatting dengan teman di dunia maya yang telah akrab (Spears \& Lea dalam Van Dijk, 1999:213).

Di luar variabel penelitian, terdapat "variabelvariabel lain" yang berpengaruh terhadap persahabatan mahasiswa di dunia maya. Variabel tersebut, antara lain, penggunaan fasilitas internet di luar chat, tarap kemampuan responden membina hubungan di internet (lihat Irwin \& Moore, 1994:2231; Bungin, 2006:167), kemampuan mengoperasikan komputer dan menjalankan program internet, serta kemampuan responden mengakses komputer (Kandell dalam Anderson, 2002 ${ }^{12}$; Van Dijk, 1999 :148). Seluruh variabel penelitian ini mengenai komunikasi antarpribadi bermedia internet pengaruhnya terhadap persahabatan di dunia maya berbeda dengan

Gambar 3 :

Model Pengaruh Komunikasi Antarpribadi Bermedia internet terhadap Persahabatan di Dunia Maya

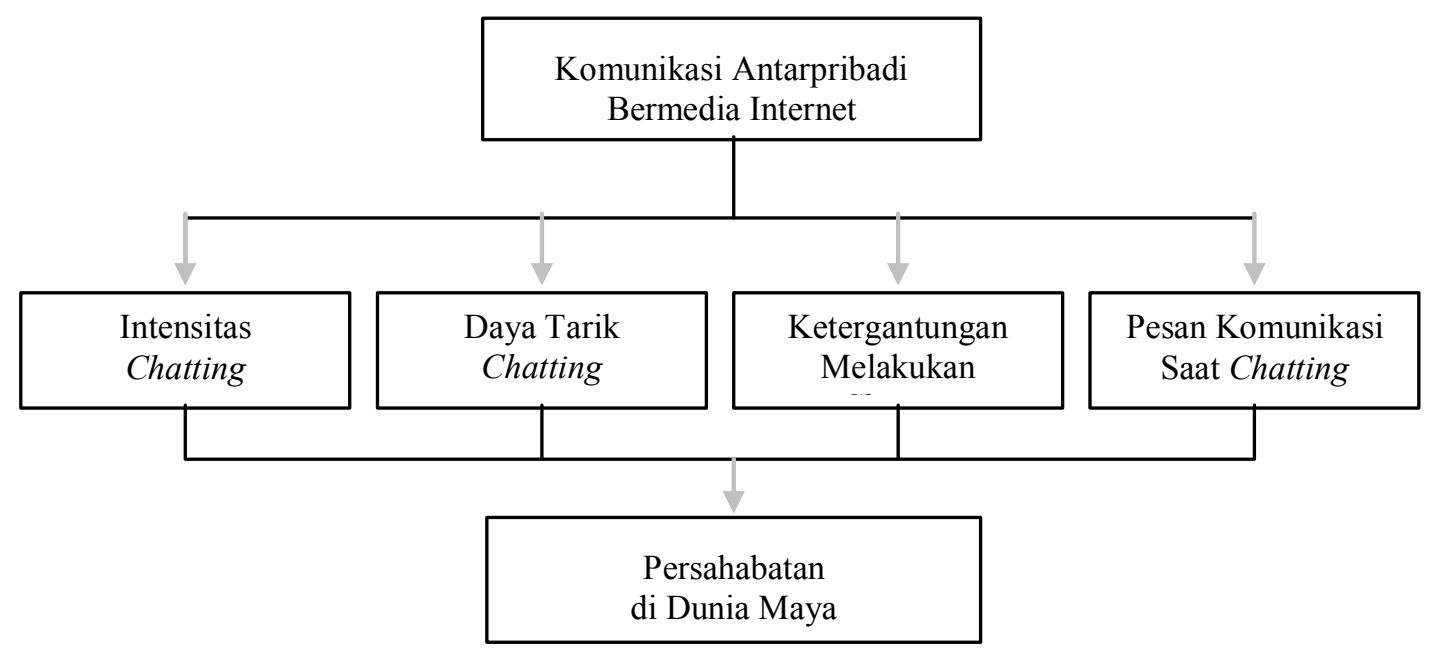


penelitian yang dilakukan oleh peneliti lain seperti Haythornthwaite (2000), Lee \& Chan (2001), Maria (2003), dan Chan \& Cheng (2004).

Penelitian ini memperoleh konsep baru mengenai pengaruh secara bersamaan antara intensitas chatting, daya tarik chatting, ketergantungan melakukan chatting, pesan komunikasi pada saat chatting terhadap persahabatan mahasiswa di dunia maya. Dari hasil wawancara diperoleh persahabatan di dunia maya (online friendship) yang dibangun melalui komunikasi antarpribadi bermedia internet merupakan kelengkapan dari persahabatan yang telah ada, karena pelakunya ternyata melakukan juga persahabatan tatap-muka. Hasil penelitian ini menambah konsep baru dan model dalam ilmu komunikasi seperti pada gambar 3 .

\section{Kesimpulan dan Saran}

\subsection{Kesimpulan}

\subsubsection{Kesimpulan Umum}

(1) Komunikasi antarpribadi (interpersonal communication) bermedia internet berpengaruh secara signifikan terhadap persahabatan di dunia maya. Hasil penelitian ini mendukung perspektif struktural fungsional, sebagaimana pandangan Merton, pengaruh itu bersifat fungsional dan disfungsional.

(2) Komunikasi antarpribadi melalui chat di internet memadukan kebutuhan untuk berhubungan secara sosial dengan media komunikasi yang berkembang pesat melalui internet. Hasil penelitian ini mendukung teori hyperpersonal yang memandang Internet sebagai sarana komunikasi yang memiliki berbagai kelebihan sehingga dapat mengimbangi kelebihan komunikasi yang dilakukan secara tatap-muka. Karena itu, hasil penelitian ini menolak teori sosial presence yang menganggap komunikasi melalui teks memiliki interaktivitas sangat rendah.

(3) Media internet meluaskan secara revolusioner jangkauan komunikasi yang bersifat lokal menjadi global. Hasil penelitian ini menunjukkan internet tidak serta-merta membuat penggunanya berkomunikasi antarpribadi melalui fasilitas chat secara global.

(4) Anonimitas komunikasi antarpribadi melalui chat di internet meningkatkan kemampuan berekspresi yang menambah keluasan dan kedalaman pesan. Hasil penelitian ini mendukung teori penetrasi sosial (social penetration theory) yang menjelaskan bahwa keluasan dan kedalaman pesan komunikasi sesuai dengan tahapan hubungan persahabatan.

(5) Anonimitas melonggarkan kendali sosial dalam komunikasi antarpribadi di dunia maya yang membuka peluang tumbuhnya komunikasi yang semu. Hasil penelitian ini menunjukkan komunikasi yang terjadi bersifat disfungsional.

(6) Persahabatan di dunia maya (online friendship) yang dibangun melalui komunikasi antarpribadi bermedia internet merupakan kelengkapan dari persahabatan yang telah ada, karena pelakunya ternyata melakukan juga persahabatan tatap-muka. Persahabatan di dunia maya digunakan untuk memelihara persahabatan tatap-muka yang terkendala karena jarak atau waktu. Sebaliknya, pertemuan tatap-muka menjadi mekanisme untuk memeriksa data dan informasi yang diperoleh secara online.

\subsubsection{Kesimpulan Khusus}

(1) Intensitas chatting di internet berpengaruh terhadap persahabatan mahasiswa di dunia maya. Intensitas chatting tersebut ditunjukkan oleh frekuensi maupun durasi chatting di internet yang dilakukan mahasiswa cukup tinggi. Oleh sebab itu, dapat dimengerti apabila intensitas chatting berpengaruh terhadap keeratan persahabatan mahasiswa di dunia maya.

(2) Daya tarik chatting di internet berpengaruh terhadap persahabatan mahasiswa di dunia maya. Daya tarik chatting itu ditunjukkan oleh rasa tertarik responden terhadap berbagai kelengkapan yang terdapat dalam fasilitas chat. 
Chatting juga menarik mereka karena peluang mendapatkan teman secara online dan memperoleh manfaat dari kecepatan mengirim dan menerima informasi. Berbagai kelengkapan dan manfaat yang diperoleh oleh mereka berakibat pada peningkatan kemampuan mengekspresikan diri dalam menjalin hubungan persahabatan di dunia maya.

(3) Ketergantungan melakukan chatting di internet berpengaruh terhadap persahabatan mahasiswa di dunia maya. Umumnya mahasiswa yang menjadi responden memiliki tingkat ketergantungan yang ringan dalam melakukan chatting. Chatting sebagai sarana berhubungan antarpribadi internet merupakan hal yang sangat menarik, namun demikian hanya mereka yang memiliki fasilitas untuk mengakses internet dan memiliki keterampilan komputer serta mengerti perangkat lunak internet yang dapat memanfaatkan sarana ini dengan optimal. Chatting di internet merupakan salah satu fasilitas yang sangat bermanfaat untuk berhubungan secara antarpribadi sekaligus sulit untuk dilakukan, sehingga dapat dimengerti apabila jumlah responden yang mengalami ketergantungan melakukan chatting di internet sedikit.

(4) Pesan komunikasi saat chatting di internet berpengaruh terhadap persahabatan mahasiswa di dunia maya. Pesan yang dibahas dalam chatting meliputi topik-topik yang beragam dan dibahas secara mendalam di antara mereka yang melakukan chatting dengan sahabat mereka di dunia maya.

(5) Intensitas chatting, daya tarik chatting, ketergantungan melakukan chatting, dan pesan komunikasi saat chatting di internet secara bersamaan berpengaruh terhadap persahabatan mahasiswa di dunia maya. Kontribusi pengaruh dari keempat faktor tersebut bila dibandingkan satu sama lainnya, pengaruhnya berbeda-beda. Melihat hasil pengaruh dari keempat faktor tersebut terhadap persahabatan mahasiswa di dunia maya, pesan komunikasi saat chatting paling besar pengaruhnya dibandingkan dengan intensitas chatting, daya tarik chatting, dan ketergantungan melakukan chatting.

\subsection{Saran}

\subsubsection{Saran Teoretis:}

Peran teknologi komunikasi yang berkembang pesat semakin penting dalam komunikasi antarpribadi bermedia internet menggunakan fasilitas chat. Seiring dengan semakin banyak pengguna internet di masyarakat, disarankan agar di masa datang diteliti komunikasi antarpribadi yang menggunakan fasilitas lain selain fasilitas chat di internet, seperti newsgroup, blog, email, serta mencakup berbagai segmen pengguna internet yang berbeda. Dengan demikian diharapkan akan terus memperluas dan memperdalam pengertian mengenai proses-proses komunikasi yang terjadi di masyarakat, dan akan semakin banyak penelitian yang meneliti modus komunikasi baru menggunakan internet, sehingga akan berdampak pada bertambahnya khazanah pengetahuan ilmu komunikasi.

\subsubsection{Saran Praktis:}

(1) Untuk mempermudah akses terhadap internet perlu ada prakarsa dari berbagai lembaga seperti: pemerintah, pendidikan dan institusi bisnis, sehingga diharapkan informasi dan komunikasi semakin merata, baik secara teknologis maupun isinya.

(2) Pemanfaatan fasilitas chat di internet yang digunakan atas inisiatif pribadi dosen atau mahasiswa di perguruan tinggi untuk melakukan bimbingan akademik, konsultasi tugas akhir dan aktivitas akademik lainnya, perlu mendapat perhatian dari birokrat kampus, sehingga dapat difasilitasi dan menjadi satu bagian pelayanan kampus yang terintegrasi. Dengan demikian, hubungan antara dosen dan mahasiswa serta unsur lainnya, tidak saja menggunakan bentuk-bentuk komunikasi yang konvensional yang mempersyaratkan adanya pertemuan secara tatap muka (face to face) melainkan dapat diselenggarakan secara virtual. 
(3) Bagi mereka yang mengalami kendala membangun hubungan antarpribadi secara tatap-muka dapat memanfaatkan sarana komunikasi online untuk meningkatkan hubungan antarpribadi mereka menjadi lebih bermakna. Namun mereka yang ingin memanfaatkan sarana komunikasi tersebut perlu memahami karakteristik hubungan yang terbangun di atasnya. Karena itu pihak-pihak yang berkepentingan perlu berpartisipasi untuk menjaga agar media Internet yang digunakannya berkontribusi pada pembentukan hubungan antarpribadi di antara mereka.

\section{Catatan Akhir}

1 Kompas. 2004. "Berbagi Kasih di Jagat Maya," 29 Februari

2 Scott, Craig.2001. Media Choice in Library Reference Communication Interactions .http://www.gslisl. utexas.edu/ Ssoy/newtechnologies/soypaper1.htm. [4/7/ 2006].

3 Ferris, Pixy. 1997. Whatt is CMC? An Overview of Scholarly Definitions. $<$ http: www. december. com $/ \mathrm{cmc} /$ $\mathrm{mag} / 1997 /$ jan/ferris/html>.[12/01/2005].

4 Kompas. 2002. "Dari Chatting Menuju Pelaminan." 2 April.

5 Kurnia, Kafi. 2003, “Chatting”. Kompas Cyber Media. (KCM) melalui <www.kompas co.id/kcm/kafi/ $\mathrm{kf} 44 \mathrm{htm}>[23 / 08 / 04]$.

6 Anderson, Keith J. 2002.Internet Use Among College Students: an Exploratory Study. Rensselaer Polytechnic Inst., Troy, N.Y. <http://www.rpi.edu $>$ [20/01/ $02\}$.

7 Anderson, Keith J. 2002.Internet Use Among College Students: an Exploratory Study. Rensselaer Polytechnic Inst., Troy, N.Y. < http://www.rpi.edu $>$ [20/01/02\} .

8 Young, Kimberly S. \& Robert C. Rodgers.1998. Personality Traits Associated With Its Development. University of Pittsburgh at Bradford. Paper presented at the $69^{\text {th }}$ annual meeting of the Eastern Psychological Association in April 1998. < $\underline{\text { http:// }}$ www.netaddiction.com $>$ [22/09/04].

9 Kompas. 2004. “Persahabatan Itu Penting.” 23 Juli.

10 Daftar Pengunjung Kubus Net, 5 Maret 2005.

11 Young, Kimberly S. \& Robert C. Rodgers.1998. Personality Traits Associated with Its Development. Uni- versity of Pittsburgh at Bradford. Paper presented at the $69^{\text {th }}$ annual meeting of the Eastern Psychological Association in April 1998. $<$ http:// www.netaddiction.com>. [22/09/04].

12 Anderson, Keith J. 2002. Internet Use Among College Students: an Exploratory Study. Rensselaer Polytechnic Inst., Troy, N.Y. Melalui <http:// $\underline{\text { www.rpi.edu }>}$ [20/01/02].

\section{Daftar Pustaka}

Abrar, Ana Nadhya. 2003. Teknologi Komunikasi: Perspekstif Ilmu Komunikasi. Yogyakarta: LESFI.

Athari, Nonni Sri. 2004. "Internet Addiction Disorder: Pengaruhnya Terhadap Kehidupan Akademik, Sosial, dan Keuangan, serta Karakteristik khalayak Mahasiswa yang Mengalaminya". Jurnal Thesis. Departemen Ilmu Komunikasi, Fakultas Ilmu Sosial dan Ilmu Politik, Universitas Indonesia, III (1) : 175-200.

Baldwin, John R., Perry, S.D., \& Moffit, M.A. 2004. Communication Theories for Everyday Life. Boston: Pearson Education Inc.

Bromberg, Heather. 1998. Are MUDs Communities? Identity, Belonging and Consciousness in Virtual Worlds. Dalam Rob Shields (eds.). Cultures of Internet: Virtual Spaces, Real Histories, Living Bodies. Wiltshire: Sage Publications.

Bungin, Burhan. 2006. Sosiologi Komunikasi: Teori, Paradigma, dan Diskursus Teknologi Komunikasi di Masyarakat. Jakarta: Prenada Media Grup.

Chan, Darius K.S., \& Cheng, Grand H.-L. 2004. “A Comparison of Offline and Online Friendship Qualities at Different Stages of Relationship Development". Journal of Social and Personal Relationship. Sage Publications, 21 (3):305-320.

DeVito, Joseph A. 1997. Komunikasi Antarmanusia. Terjemahan Agus Maulana. Jakarta: Profesional Books. 
Haythornthwaite, Caroline. 2000. "Online Personal Network : Size, Composition and Media Use Among Distance Learners". Journal of New Media and Society. Sage Publications, 2 (2): 195-226.

Irwin,Harry. \& Moore, Elizabeth.1994. Managing Corporate Communication. St Leonards: Allen \& Unwin.

Knapp, Mark L. \& Gerald R. Miller. 1994. Handbook of Interpersonal: Sage Publications.

LaQuey, Tracy. 1997. Sahabat Internet. Terjemahan Hans J.W. Bandung: Institut Teknologi Bandung.

Lee,W., \& Chan, B. (2001). Internet as a Facilitator of Social Relationship: A Study of Young Singaporean's Online and Offline Friendship. Paper Presented at the Internet and development in Asia, Internet Political Economy Forum, September 14-15, 2001, Singapore. Dalam Lee, M. \& Kuo, E.C.Y. 2002. "Internet and Displacement Effect: Children's Media Use and Activities in Singapure". JCMC 7 (2). Melalui $<$ http://www.ascusc.org./jcmc/vol7/ issue2/singapore.html $>[28 / 07 / 04]$.

Littlejhon, Stephen W. $1999 . \quad$ Theories of Human Communication. California: Wadsworth Publishing Company.

Maria, Stelly. 2003. "Hubungan Antarpribadi melalui Komunikasi Antarpribadi via Internet." Tesis Program Pascasarjana Ilmu Komunikasi, Jurusan Ilmu Komunikasi, Fakultas Ilmu Sosial dan Ilmu Politik, Universitas Indonesia.

Nguyen, Dan Thu, \& Alexander, J. 1998. "The Coming of Cyberspacetime End of the Polity." in Rob Shield (eds.). Cultures of Internet: Virtual Spaces, Real Histories, Living Bodies. Wiltshire : Sage Publications.

Poloma, Margaret M. 2000. Sosiologi Kontemporer. Tim Penerjemah Yayasan Solidaritas Gajah Mada. Jakarta: PT RajaGrafindo Persada dan YASOGAMA.
Rakhmat, Jalaluddin. 1996. Psikologi Komunikasi. Bandung: PT. Remaja Rosdakarya.

Rheingold, Howard. 1993. The Virtual Community: Home Steading on the Electronic Frontier. New York: Harper Perennial.

Rintel, E. Sean, Mulholland, J., \& Pittam, J. 2001. "First Thing First : Internet Relay Chat Opening". Journal of Computer-Mediated Communication, 6 (3). Melalui < htpp:// jemc.indiana.edu/vol6/issue3/rintel.html>

Rusidi. 1992. Dasar-Dasar Penelitian dalam Rangka Pengembangan Ilmu. Bandung: Program Pascasarjana Universitas Padjadjaran.

Sendjaja, S. Djuarsa (ed.).1994. Teori Komunikasi. Jakarta: Universitas Terbuka.

Shields, Rob. 1998. Cultures of Internet: Virtual Spaces, Real Histories, Living $\quad$ Wiltshire: Sage Publications.

Sidharta, Lani. 1996. Internet Informasi Bebas Hambatan. Jilid 2. Jakarta: PT. Gramedia.

Sitepu, Nirwana S.K. 1994. Analisis Jalur (Path Analysis). Bandung: FMI Universitas Padjadjaran.

Sopyan, Yayan. 2003. Romansa Cyber: LikuLiku Hubungan Romantis di Internet. Jakarta: Gagas Media.

Tubbs, Stewart L., \& Moss, S. 1996. Human Communication: Prinsip-Prinsip Dasar. Terjemahan Deddy Mulyana dan Gembirasari. Bandung: PT. Remaja Rosdakarya.

Van Dijk, Jan. 1999. Network Society, Social Aspect of New Media. Terjemahan Leontine Spoorenberg. London: Sage Publications.

Wright, Charles R. 1995. Sosiologi Komunikasi Massa. Jalaluddin Rakhmat (Penyunting). Bandung: CV. Remadja Karya. 


\section{Surat Kabar dan Internet:}

Anderson, Keith J. 2002. Internet Use Among College Students: an Exploratory Study. Rensselaer Polytechnic Inst., Troy, N.Y. Melalui $<$ http://www.rpi.edu $>$ [20/01/02].

Bechar-Israeli, Haya.2004. From $<$ Bonehead $>$ to $<$ cLonehEAD> : Nicknames, Play, and Identity on Internet Relay Chat $\langle 1\rangle$. Melalui $<$ http://www.mshya@pluto.mscc.huji.ac.il $>$ [03/06/2004].

Ferris, Pixy. 1997. Whatt is CMC? An Overview of Scholarly Definitions. Melalui $<\mathrm{http}: / /$ www. december. com/cmc/mag/1997/jan/ferris/ $\mathrm{html}>[12 / 01 / 2005]$.

Kompas. 2002. "Dari Chatting Menuju Pelaminan." 2 April.

Kurnia, Kafi. 2003. “Chatting”. Kompas Cyber
Media (KCM). Melalui $<\underline{\text { http:// }}$ www.kompas.co.id./kcm/kafi/kf44.htm $>$ [23/ 08/04].

Kompas. 2004. "Berbagi Kasih di Jagat Maya." 29 Februari.

Kompas. 2004. "Persahabatan Itu Penting." 23 Juli 2004.

Scott, Craig.2001. Media Choice in Library Reference Communication Interactions .http:// www.gslisl.utexas.edu/ s soy/ newtechnologies/soypaper1.htm.[4/7/2006].

Young, K.S. \& Rodgers, R. C. 1998. Personality Traits Associated With Its Development. University of Pittsburgh at Bradford. Paper presented at the $69^{\text {th }}$ annual meeting of the Eastern Psychological Association in April 1998. Melalui $<$ http://www.netaddiction.com $>[22 /$ 09/04 
